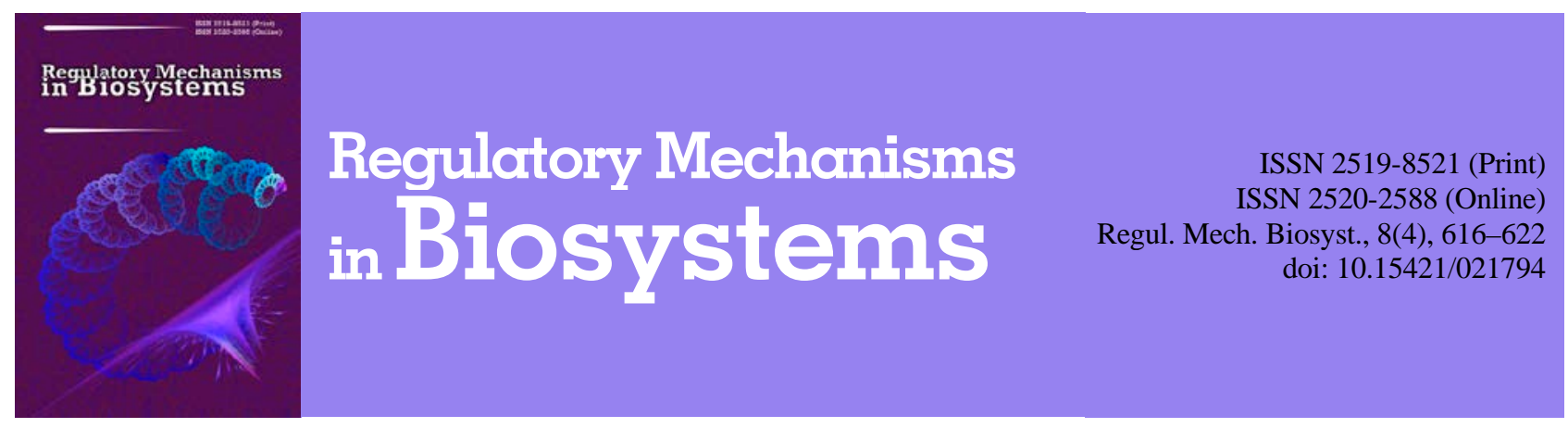

\title{
In vitro rhizogenesis of sugar beet microclones
}

\author{
V. V. Polishchuk*, L. M. Karpuk**, V. P. Mykolaiko***, A. A. Polishchuk*, I. I. Mykolaiko*** \\ *Uman National University of Horticulture, Uman, Ukraine \\ **Bila Tserkva National Agrarian University, BilaTserkva, Ukraine \\ ***Pavlo Tychyna Uman State Pedagogical University, Uman, Ukraine
}

\section{Article info}

Received 30.09.2017

Received in revised form 26.10.2017

Accepted 29.10.2017

Uman National University of Horticulture,

Instytutska str., 1 ,

Uman, 20305, Ukraine.

Bila Tserkva National Agrarian University, Soborna sq., 8/1, BilaTserkva, 09100, Ukraine.

Pavlo Tychyna Uman State Pedagogical University, Sadova str., 2,

Uman, 20300, Ukraine. Tel.: +38-050-858-74-54. E-mail: irinamikolaiko@i.ua

Polishchuk, V. V., Karpuk, L. M., Mykolaiko, V. P., Polishchuk, A. A., \& Mykolaiko, I. I. (2017). In vitro rhizogenesis of sugar beet microclones. Regulatory Mechanisms in Biosystems, 8(4), 616-622. doi:10.15421/021794

The features of rhizogenesis of male-sterile simple hybrids, maternal components of sugar beet heterozosis hybrid and O-types of Darinka variety grown from seeds were investigated. The paper presents the results of studying the main basic nutrient media (B5-A1, B5-A2, B5-A3, B5-A4, B5-A5 and B5-A6) for rhizogenesis, in which the content of macro- and microelements has been reduced by three times, the content of sucrose is reduced by almost 6 times, the amount of agar is reduced by almost five times, while the vitamin PP content is increased by 1.6 times, and the BAP is completely removed. The largest number of rooted microclones was obtained with NAAs by the high indexes of average number of roots and medium indexes of average roots length. To the second, by the number of rooted microclones is assigned, media of 2,4-D, 2,4-DB containing, potassium salt of NAA and IBA were classified, while IAA was characterized by a lower efficiency. The possibilities of regulation of growth and development processes of sugar beet in vitro explants in favor of undifferentiated growth at the stage of proliferation or organogenesis (hemo- and rhizogenesis) have been determined. To improve the quality of rooting of sugar beet plants-regenerants, we have developed the method for dimming agarized nutrient medium with methylene blue at a $0.05 \%$ concentration, which made it possible to reduce the inhibitory effect of light on the development of lateral roots. The average index of microroots rooting for MS-forms was $81.5 \%$. The technology of adaptation of micro-roots rooting was developed, in which the plant material at the initial stage of growth had slight morphological changes in the puffer apparatus and stem, but by the end of the vegetation, the plants acquired the appearance characteristic of the donor plants of explants. The clone's resiliency is reached about $100 \%$ in the soil. According to the variability of morphological characteristics in reproduced in vitro sugar beet plants of the MS-forms of the Darynka hybrid, all the plants grown from the regenerants were more, than seed progeny from seed sowing of the same component obtained as a result of the attachment of sterility to the corresponding O-type. It has been found that in vitro cultivation has not weakened, and in some cases even increased the mitotic index of meristem cells of young roots of sugar beet. Most genotypes have reduced the number of pathological mitoses, apparently due to the activation of reparative systems, but did not extend the duration of individual phases of mitosis; without increasing the number of anaphase with bridges and fragments, but changed the number of anaphases with other chromosomal abnormalities. In all variants of the experiment, where activation of growth processes has been observed, the lowest variability of the signs is observed, that is, under the influence of stimulants, which are part of nutrient media, obviously there is unification of cell populations.

Keywords: auxins; cytokinins; ex vitro adaptation; micropropagation

\section{Introduction}

Sugar beet (Beta vulgaris L.) is a plant of the Amaranthaceae family, one of the most important industrial crops in Ukraine which is the raw material base of the sugar industry, it is one of the main sugarbearing plants. Biological features, a two-year cycle of development, a high level of heterozygosity and cross-pollination are complicating the process of new varieties of sugar beets obtaining by classical selection methods (Putnik-Delic et al., 2013; Yildizl et al., 2013, Kagami et al., 2016). One of the most promising ways to intensify the breeding process is the use of modern biotechnology methods that are used both for the propagation and preservation of valuable genotypes, and for the creation of new source materials of sugar beet with economically valuable features. For mass production of plants the method of clonal micropropagation is used, which provides a high reproductive rate, the selection of plants with selective and valuable features in vitro conditions, and the improvement from pathogens (Mishutkina and Gaponen- ko, 2006; Kolomiets, 2008; Krylovskaya, 2012). The basic principles of the method of microclonal propagation of sugar beet plants, as well as many other crops, have already been developed (Ritchieet al., 1989; Gurel et al., 2008; Neelwarne, 2013). It has been established that microclone propagation process, regardless of the type of explants, can be divided into four main stages: sterilization of plant material and introduction of explants into the nutrient medium; proliferation (rapid reproduction); hemo- and rhizogenesis (inducing the development of microparos and roots) and adaptation to non-sterile ex vitro conditions (Sullivan et al., 1993; Gurel and Wren, 1995; Kosenkoet al., 2008). This is possible in planar (agar) and suspension cultures, although agar cultures are preferable in seed breeding practice (Nagl et al., 2010; Rizkalla et al., 2012; Kosenkoet al., 2008). However, it should be noted that the published data are sometimes not fully supported with the introduction materials. The issues of explants' cultivation conditions need further development. The issues of optimization of nutrient media in terms of macro- and microsalts, vitamins, carbohydrates and phytohormones 
(auxins, cytokinins and gibberellins) correlation at all stages of reproduction and on specific genotypes in particular require significant improvement (Wright and Penner, 1998; Zhang et al., 2001; Joersbo, 2007).

It is well known that during the formation and growth of roots a series of various interdependent biochemical, physiological and histological processes take place. The proximity of cells to the vascular tissue is among the anatomical factors that contribute to laying the root primordia. Vital capacity of in vitro rooted plants is largely conditioned by the place of the roots' laying. In some variants, even a sufficient number of in vitro rooted plants result in almost complete destruction of plants in non-sterile conditions. Three basic specific stages regarding nutrition and cultivation conditions are defined in the rooting process, namely: induction, initiation, roots growth. Under successful combination of the medium and conditions for rooting and bringing them in line with the plants genotype, the duration of the first two phases is 10 15 days (Kosenkoet al., 2008; Taski-Ajdukovic et al., 2012).

The previous experiments reveal that the decrease in light intensity accelerates the beginning of the roots' formation. We can assume that the light shortage generated specific protein receptors with high affinity for auxin and increased activity of peroxidase and IAA oxidase in the early stages of laying the roots in response to stressful conditions. Lack of oxygen in the nutrient media used for shoots rooting in vitro inhibits the development of root hairs as well. Insufficient development of root hairs is particularly dangerous during the test-tube adaptation of plants to non-sterile ex vitro conditions (Polischuk, 2012; Polischuk et al., 2012).

The goal of our work was to improve the in vitro methods for sugar beet crop. To achieve this goal, the following tasks had to be solved:

- to determine the optimum nutrient medium and cultivation conditions;

- to find out the possibilities of regulation of growth and development processes of sugar beet explants in vitro;

- to develop the technology of adaptation of rooted microclines.

\section{Materials and methods}

The objects of research were male-sterile simple hybrids, the maternal component of the heterozosis hybrid of sugar beet and O-types of the Darinka variety, which grown from seeds, pre-selected in thermal stress conditions (lowered germination temperature), are used as a provocative background for resistance to "blossom". The studies were conducted in several directions: the ability to callusogenesis in different explants, the intensity of regeneration and rooting of sugar beet regeneration plants in different variants of nutrient medium.

For the explants we used two-week sprouts, which were cut in a laminar box from a sterilized sprouted seed with a steamed scalpel at $180-200^{\circ} \mathrm{C}$ and immediately transferred by sterilized (along with the scalpel) tweezers to the nutrient medium, that was prepared according to the Gamborg and Eveleg (B5) which was modified by sulfuric acid iron $\left(\mathrm{FeSO}_{4} \times 7 \mathrm{H}_{2} \mathrm{O}\right)-27.8 \mathrm{mg} / \mathrm{l}$ with antioxidant Na2EDTA - $37.3 \mathrm{mg} /$, and also additionally administered of Mio-inositol $-100 \mathrm{mg} / \mathrm{l}$ and an increased content of carbohydrate source up to $27 \mathrm{~g} / \mathrm{l}$ of sucrose. In each of them we cut off the apex of shoots with cotyledons with 20-30 mm length. In each variant, in Petri dishes we planted 30 calluses in three replicates. Male sterile simple hybrids, maternal components of sugar beet heterosis hybrid and O-types were grown from the seeds, preselected in thermal stress condition (reduced germination temperature) used as a provocative background for resistance to "bolstering". The explants were harvested from seedlings obtained from the seed that had grown on "bolstering" resistant plants. For this purpose, these sterilized seedlings were placed into a sterile Petri dish and the shoot apex with cotyledons, 20-30 mm length was cut off with a sterile scalpel. Apex with cotyledons and hypocotyls top were carried into glass containers with B5 - 173 basic medium with $0.25 \mathrm{mg} / \mathrm{l} \mathrm{BAP}$. The first transplantation was performed in the third ten day period of December -27 days after the introduction, and the subsequent subcultivation were conducted every 15 days, which provided a virtual opportunity to make 24 subcultivations a year. Microclones rooting started in the second ten day period of June after the 10th passage. Microclones that had reached about $2.0-2.5 \mathrm{~cm}$ height and had 1-2 leaves were put into sterile glass vessels (jars) into the medium for rhizogenesis, in which they were rooted under standard temperature of $25^{\circ} \mathrm{C}$ and 16 hour photoperiod, but with reduced to 2.7 kiloluxes intensity lighting. However, three weeks after sugar beet cultivation in vitro the medium was replaced with a fresh one, but with the same composition. Accounting the rooted microclones and the number of roots on a microshoot, measuring the length of the newly formed roots were performed five weeks after the rooting.

However, we applied cytological methods of chemical components to determine the ploidy, since determining the ploidy using "Partec" analyser technology is relatively costly. At the initial stage the material was fixed at $0.03 \%$ o-xiquinoline solution for three hours at $2-4{ }^{\circ} \mathrm{C}$. Then the objects were washed with distilled water and macerated for 25 minutes in a mixture of $96 \%$ alcohol, icy acetic acid and $25 \%$ hydrochloric acid at a ratio of $3.5: 1: 0.5$. The next phase of work included washing the material with distilled water and its transfer to an object slide into a drop of $3 \%$ ossein, heating on a spirit lamp and covering the cover glass. We studied the cytogenetic parameters on permanent strangled preparations made from young roots of sugar beet by the standard method. The total number of the examined cells in each chemical, MI, the number of cells that divide and are in a certain phase of mitosis and PM were taken into account in the chemicals study. After that, we calculated MI (the ratio of the number of dividing cells and the total number of cells in the chemical), share prophase and PM.

Statistical processing of experimental data was carried out using the method (Fisher, 2006), using Statistical Software 6.0 from StatSoft.

\section{Results and discussion}

It is common knowledge that one of the main factors that influences the induction of rhizogenesis in in vitro crops is the composition of the nutrient medium (Mishutkina and Gaponenko, 2006; Ryabovol et al., 2012). The choice of the environment was largely due to the type of desired morphogenesis. In doing so, to achieve the positive results for each development phase, the genotype and the term of micropropagation can only be selected by selecting the appropriate optimum nutrient medium and the ratio of auxins and cytokinins in it. Often used in the crop of cells and tissues are the media which are based on the prescriptions of Gamborg and Eveleg, Linsmeier and Skoog, Murasig and Skoog, Heller, Shenk and Hildebrandt and White (Mishutkina and Gaponenko, 2006). All of them were developed and tested in the 1930s-1960s. Most other modern prescriptions of media are based on existing ones with variations in the content of individual components or the replacement of some of them with synthetic analogues. To stimulate rooting, they usually reduce the amount of sugar to $0.5-1.0 \%$ and eliminate the cytokinins completely, leaving only the auxins. Different sources of exogenous auxin are used as root stimulator, although rooting on the media without auxin is reported to be possible. IAA synthetic substitutes are mostly used instead of IAA since the latter destroys quickly. IAA is mainly replaced by NAA, IBA and potassium salt of the NAA which are easily soluble in water as well as in 2.4-D, 2.4-DB. In some cases they do not use the full concentration of salts, provided by the protocol, but only $0.25-0.50$ of their content while preserving the correlation which concerns primarily the rhizogenesis process. High salt concentration delayed the roots formation in vitro, which caused the need to reduce their concentration (Mezei et al., 2006; Kosenkoet al., 2008).

As the result of the conducted research, the number of nutrient medium is modified on the basis of the Gamborg and Eveleg medium (B1-B200) analyzed, which made it possible to distinguish one of the most effective B5-173 (Table 1).

Six modifications to rooting medium (B5-A1, B5-A2, B5-A3, $\mathrm{B} 5-\mathrm{A} 4, \mathrm{~B} 5-\mathrm{A} 5$ and B5-A6) remained after the reconnaissance testing in the experiment on MS microclones of maternal components of heterosis hybrids and O-types of sugar beets in the process of in vitro microclonal propagation. The content of macro- and micronutrients was three times reduced, sucrose content - almost six times reduced, and agar content - almost five times reduced in all the versions of the medium modification. Instead, vitamin PP content was 1.6 times increased and BAP was removed completely. B5-A2, B5-A3, B5-A4, B5-A5, B5-A6 media differed from the B5-A1 one only in the auxin forms 
(2.4-D, 2.4-DB, NAA, NAA potassium salt and IBA) with the same amount of other components.

\section{Table 1}

Composition of sugar beets microclones rooting basic medium compared to the reproduction medium (mg/l)

\begin{tabular}{|c|c|c|c|}
\hline \multicolumn{2}{|c|}{ Reproduction medium B5-173 } & \multicolumn{2}{|c|}{ Rooting medium B5-A1* } \\
\hline$\left(\mathrm{NH}_{4}\right)_{2} \mathrm{SO}_{4}$ & 67.0 & $\left(\mathrm{NH}_{4}\right)_{2} \mathrm{SO}_{4}$ & 22.3 \\
\hline $\mathrm{KNO}_{3}$ & 1250.0 & $\mathrm{KNO}_{3}$ & 416.6 \\
\hline $\mathrm{MgSO}_{4} \times 7 \mathrm{H}_{2} \mathrm{O}$ & 125.0 & $\mathrm{MgSO}_{4} \times 7 \mathrm{H}_{2} \mathrm{O}$ & 41.6 \\
\hline $\mathrm{NaH}_{2} \mathrm{PO}_{4}$ & 75.0 & $\mathrm{NaH}_{2} \mathrm{PO}_{4}$ & 25.0 \\
\hline $\mathrm{CaCl}_{2} \times 2 \mathrm{H}_{2} \mathrm{O}$ & 75.0 & $\mathrm{CaCl}_{2} \times 2 \mathrm{H}_{2} \mathrm{O}$ & 25.0 \\
\hline Fe-chelate $\mathrm{FeSO}_{4} \times 7 \mathrm{H}_{2} \mathrm{O}$ & 27.8 & Fe-chelate $\mathrm{FeSO}_{4} \times 7 \mathrm{H}_{2} \mathrm{O}$ & 9.3 \\
\hline $\mathrm{Na}_{2}$ EDTA (trylon $\mathrm{B}$ ) & 37.3 & $\mathrm{Na}_{2}$ EDTA (trylon B) & 12.4 \\
\hline $\mathrm{H}_{3} \mathrm{BO}_{3}$ & 1.5 & $\mathrm{H}_{3} \mathrm{BO}_{3}$ & 0.5 \\
\hline $\mathrm{MnSO}_{4} \times 4 \mathrm{H}_{2} \mathrm{O}$ & 4.5 & $\mathrm{MnSO}_{4} \times 4 \mathrm{H}_{2} \mathrm{O}$ & 1.5 \\
\hline $\mathrm{ZnSO}_{4} \times 4 \mathrm{H}_{2} \mathrm{O}$ & 1.5 & $\mathrm{ZnSO}_{4} \times 4 \mathrm{H}_{2} \mathrm{O}$ & 0.5 \\
\hline $\mathrm{B}_{1}$ & 1.0 & $\mathrm{~B}_{1}$ & 0.3 \\
\hline $\mathrm{B}_{6}$ & 1.0 & $\mathrm{~B}_{6}$ & 0.3 \\
\hline $\mathrm{C}$ & 1.0 & $\mathrm{C}$ & 0.3 \\
\hline PP & 1.0 & PP & 1.6 \\
\hline Glycine & 1.0 & Glycine & 0.3 \\
\hline Myo-inositol & 100.0 & Myo-inositol & 33.3 \\
\hline Agar & 3000.0 & Agar & 700.0 \\
\hline Sucrose & 2700.0 & Sucrose & 500.0 \\
\hline BAP & 1.0 & IAA & 1.0 \\
\hline
\end{tabular}

Note: B5-A2, B5-A3, B5-A4, B5-A5, B5-A6, media differed from the B5-A1 one only in the auxin forms (2.4-D, 2.4-DB, NAA, NAA potassium salt and IBA) with the same amount of other components; benzylaminopurine (BAP), indolyl-3-acetic acid (IAA), naphthylacetic acid (NAA), indolyl3-butyric acid (IBA), 2,4-dichlorophenoxyacetic acid (2,4-D), 2,4-dichlorophenoxybutyric acid (2,4-DB), line of securing sterility (O-type), mitotic index (MI), pathological mitosis (PM).

Depending on the source of auxin, sugar beet microclones in vitro rooting was different. According to ANOVA dispersion analysis, auxin modified media can be divided into three groups by the number of rooted microclones. The largest number of rooted microclones was obtained under using NAA with high rates of the average number of roots and average figures for the average roots length. The second group, distinguished by the number of microclones rooted, comprised media with 2.4-D, 2.4-DB, potassium salt NAA and IBA, while IAA was characterized by lower efficiency (Table 2). In the variant with NAA clearly defined germs were visible on the 4th day and the first roots appeared on the 6th day. However, NAA began to inhibit the root system development under prolonged exposure (10-15 days). Similar, but less distinct phenomena were observed in the variants with other sources of auxin. Thus, according to the average number of roots per one in vitro plant three, the auxin modified media can be combined into three efficiency groups though the content is different. High average numbers of roots were in the variants with NAA and the IOA, the second rated was the medium with potassium salt NAA, while the media with IBA, 2.4-D and 2.4-DB were less efficient.

\section{Table 2}

Sugar beet microclones in vitro rooting depending on the auxin source $(n=3)$

\begin{tabular}{lccc}
\hline \multicolumn{1}{c}{ Rhizogenesis medium } & $\begin{array}{c}\text { Number of rooted Roots average } \\
\text { microclones, } \%\end{array}$ & $\begin{array}{c}\text { Roots average } \\
\text { number, pcs. }\end{array}$ & length, cm \\
\hline B5-A1 - IAA & 42.0 & 5.4 & 2.0 \\
B5-A2 - 2.4-D & 55.3 & 3.6 & 3.2 \\
B5-A3 -2.4-DB & 53.0 & 5.4 & 4.0 \\
B5-A4 - NAA & 65.2 & 16.1 & 3.4 \\
B5-A5 - potassium salt & 57.1 & 11.3 & 2.7 \\
NAA & 53.8 & 14.0 & 3.5 \\
B5-A6 - IBA & 4.8 & 2.1 & 1.8 \\
LSD $_{05}$ &
\end{tabular}

The difference in the media efficiency in terms of their influence on the average root length was almost completely levelled. However, it is the number of microclones rooted that is the critical performance characteristic of the given medium since the aim of the experiment was accelerated vegetative propagation in vitro in the unique sugar beets plant selected on provocative background, though the number of testtube plants adopted to non-sterile ex vitro conditions able to grow to the size ensuring testes development, capable of flowering and producing seed if reproduced genotypes should be considered as well.

To improve the quality of sugar beet regenerant plants rooting, we developed a method of darkening the agar nutrient medium using methylene blue dye. The idea of darkening the medium was used in some fruit crops. Methylene blue dye at concentrations of $0.01 \%$ and $0.05 \%$ was added to B5-A6 with IBA medium (Fig. 1).

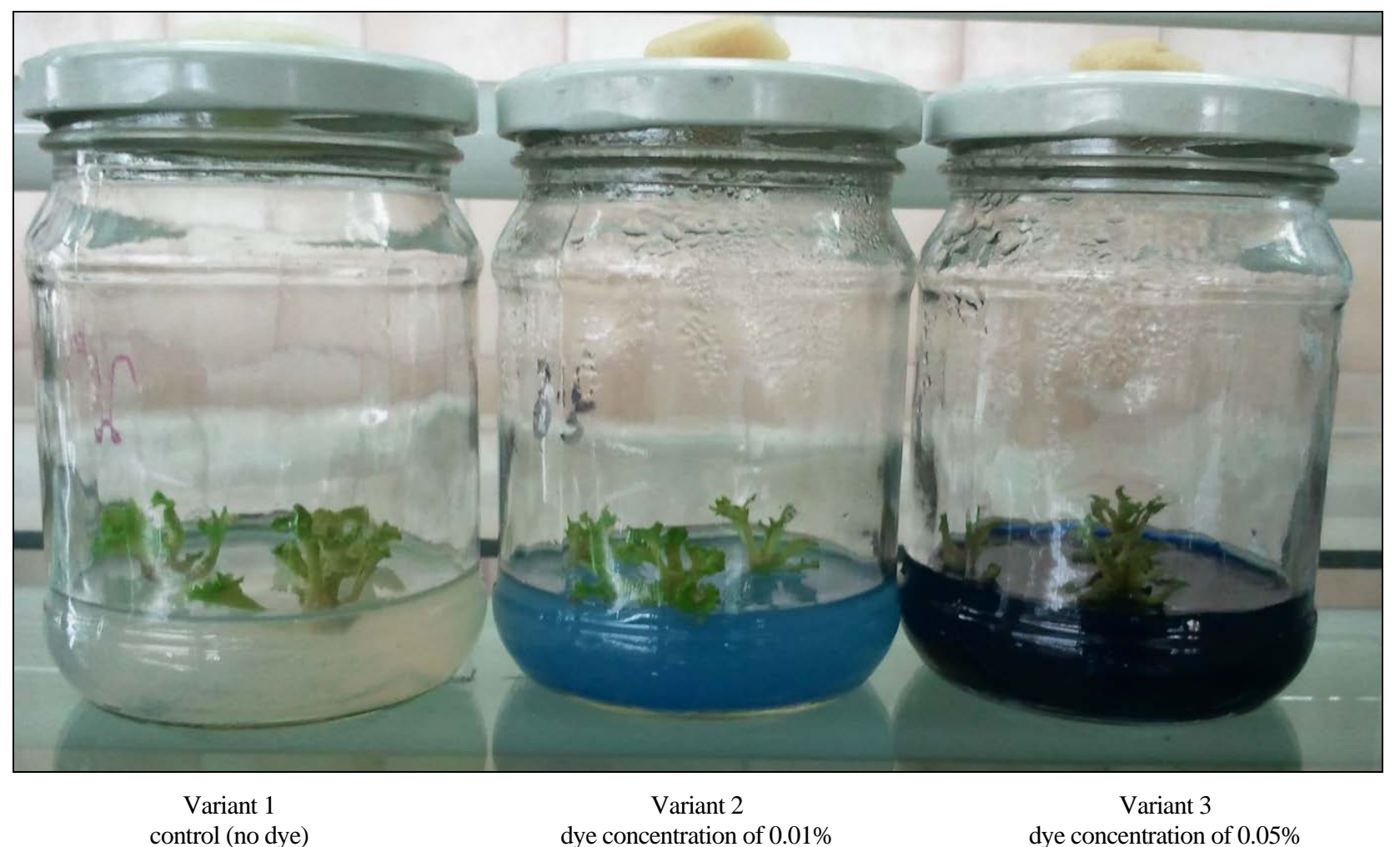

Fig. 1. Test-tubed regenerant plants of sugar beets rooting room № 587 k 19 on medium B5-A6-IBA with the addition of methylene blue dye 618 
The following variants were included into the scheme of the experiment on studying the effect of nutrient medium darkening on the process of rhizogenesis of sugar beet test-tubed regenerant plants. It was established that with the addition of dye, the methylene blue process of rooting proved the significantly better in all variants of the experiment. However, the best results of root formation were observed in the third variant test-tubed plants with adding methylene blue dye at a concentration of $0.05 \%$, where the rhizogenesis was $78-85 \%$. Pretty good performance was recorded in the second variant of the experiment with the concentration of the methylene blue dye $0.01 \%$, where the root process was $66-70 \%$. The methylene blue dye at the concentration of $0.05 \%$ colours nutrient medium more intensively, which, in our opinion, reduces the inhibitory effect of light on the development of lateral roots and increases the activity of IBA. The average rate of rooting microclones for MS-forms was $81.5 \%$.

Carrying plants from in vitro conditions into ex vitro is an important and the most labour intensive final stage of microclonal reproduction (Kosenko et al., 2008; Tomaszewska-Sowa, 2012). The best time for transplanting is when plants have roots grown sufficiently to absorb mineral elements from the soil, and their young leaves are capable of productive photosynthesis. Root size for sugar beet plant adaptation in our experiment was 5-6 cm, and the lateral roots numbered 6-8 pieces. The plants' development phase made 2-4 leaves.

To carry plants from the medium conditions into natural conditions, it is necessary to acclimatize and adapt their material to the natural conditions of temperature, light and humidity. The adaptation process from in vitro to ex vitro conditions often is critical for plants survival. Different methods of adaptation are used, in particular: adaptation of testtubed plants; plants intermediate rooting with the use of phytotrons. The first method involves the use of adaptational rooms equipped in a similar way to the cultural facilities where optimal conditions for plants growth gradually approach the natural environment to which the material will be transplanted. Two main factors should be taken into account in carrying out the adaptation: the anatomical and physiological ones, which are fundamentally different for plants grown under in vitro conditions. The first feature of the difference is the absence or reduced amount of cuticular wax, poor development of assimilating parenchyma and poor functioning of stomata apparatus. Another factor reflects the lowered photosynthesis capacity due to the cultivation on the media with carbohydrates source. In some cases, the roots of test-tubed plants have no root hairs. These features of regenerant plants cause their rapid dehydration on ex vitro transplantation from in vitro conditions, which causes the plants death.

The technology of adaptation of rooted microclones was developed, in which a mixture of perlite and sand was used as a substrate to which the necessary nutrients were introduced before planting. A mixture of perlite and sand was used for a substrate, with essential nutrients added before the transplanting of the plants . 25-30 kg of substrate with 1-2 $g$ of nitrogen active substance, $2 \mathrm{~g}$ of phosphorus and $2 \mathrm{~g}$ of potassium was applied per three quarters of perlite and a quarter of sand. Also, a good air permeability and humidity - holding ability mix containing 2 parts of soil, 1 part of peat and 1 part of humus can be used for plants as they finish growing. To enhance plants taking roots, $2-3 \mathrm{~cm}$ layer of perlite was poured on the top of the mixture. Nutrient substrate height was 7-10 cm, with the area of plants nutrition of $5 \times 5 \mathrm{~cm}$. The substrate was watered with nutrient solution, which included growth regulators stimulating rhizogenesis. We tried to keep the temperature in the phytotron within $20-25^{\circ} \mathrm{C}$ at $70-80 \%$ humidity and light period duration of 10 hours a day least. The plants planted into the substrate were covered with plastic wrap. Planting the plants into soil mix was performed by hand through making small holes and placing the roots vertically. Then we compacted the substrate around the plant, watering and covering it with film. 7-10 days later, when the plants had taken root and started growing, they were tempered. The film was removed for 10-15 minutes initially, then the time extended to $1-2$ hours. 3-4 days afterwards the film was removed completely. The regenerated plants survival reached $87 \%$ under these conditions.

30-50 days later the plants formed well-developed aerial parts and a strong root system. At this time, the plants had a height of 10-15 cm and 6-10 leaves. These plants are suitable for transplantation into the field. In the second ten day period of May the regenerated plants were planted into open ground with a mandatory shading for two days, where they were regularly irrigated and cared for. Clones survival in the soil reached about $100 \%$. The plant material at the initial stage of growth had minor morphological changes in the leaf apparatus and stem, but by the end of the growing season the plants acquired the shape typical for explanted donor plants.

It is considered that the variability observed in in vitro regenerated plants belongs to two categories: epigenetic variability in the form of short-term or long-term changes; genetic variability that arises from genomic, chromosomal and gene mutations (Miguel and Marum, 2011; Us-Camaset al., 2014). Genetic mutations are inherited and are often a manifestation of existing changes in the explants cells, though new mutations are possible too. Chromosomal abnormalities are one of the most important manifestations of these changes. Although the ploidy increase can occur during endopolyploid cell division of the source material, most polyploids and aneuploids occur during cultivation. These changes should be distinguished from the morphoses that are inherited from the effects of epigenetic changes which are often reversible and occur due to cultivation under in vitro conditions. It is also known that genetic changes in cells can be induced by auxin mutagenic action, especially by 2.4-D or cytokinins. However, changes that take place during somatic cells differentiation may be the most reliable source of genetic variability. When plant cells are cultivated in vitro, some cases of somaclonal variability i.e. different mutations, including ones with the changes in the chromosomes number, occur, resulting in loss of propagated microclones uniformity. The described changes can be both hereditary and non-hereditary (modification). Violation of correlative relationships and the fact that in vitro cell division occurs without genetically predetermined organism control that is carried out by endogenous phytohormones in an integrated plant account for somaclonal variability (Mezei et al., 2006; Penna et al., 2012). Chromosome variability of cells in vitro is among the best studied cytological disorders, like endomitosis and endoreduplication whicht causes polytene chromosomes formation, which are formed due to repeated DNA synthesis without further nucleus and cells fission (Carvalheira, 2000). Therefore, cytometric monitoring is carried out to choose appropriate medium (Pasqual et al., 2012). Reduced number of unwanted mutations and non-hereditary changes can be achieved by adjusting the concentration of exogenous phytohormones introduced in the nutrient medium instead of those regulating normal cell division in vivo. The purpose of our research was to select a nutrient medium in which the possibility of unintended spontaneous somaclonal variability would be reduced to a minimum. For marker signs monitoring somaclonal variability, the following were chosen: chromosomal aberrations and ploidity change, roots form, the degree of root crops absorption into soil, forms of leaf blades and rosettes shape.

We found that all the studied plants grown from regenerants were more uniform by the variability of morphological characteristics in the in vitro reproduced plants of sugar beet MS-forms of Daryna hybrid than the seed offspring obtained from the sowing the seeds of that very component obtained by fixing the sterility with appropriate corresponding O-type. In particular, changes in leaf rosettes were observed only in the seed offspring and in the variant with the B5-A3-2.4 DB medium with the same changes frequency of $1.1 \pm 0.1 \%$. Variations in the leaf plates morphology did not exceed $1.1 \pm 0.1$ in B5-A2-2.4-D variant under the lowest rate of $0.5 \pm 0.1$ in B5-A3-2.4-DB and B5-A5potassium salt NAA in seed control variability of $0.9 \pm 0.2 \%$. Similar effects were observed in roots absorption into soil and the number of atypical roots as well. The total amount of in vitro grown plants of MSforms of sugar beet hybrid Daryna with morphological mutations in all versions of the experiment was less than that in the seed control (Table 3).

That can account for the influence of sterility fixative pollen, which obviously was not $100 \%$ analogous, and thus it could cause some allelic or interallelic interactions which cannot prevent high quality seeds production. That is, no morphological mutation characteristics are observed in Daryna hybrid component reproduction with biotech element inclusion as compared to conventional breeding using O-type fixing sterility 
agents. The variability of the genome of all plants in general and variability of specific tissues and cells is considered to be a fundamental property of organisms. The rapid development of modern biotechnology revealed a number of facts on obtaining numerous various unpredictable changes brought out in the in vitro cultured cells. Genome endoreduplication is one of these changes.

Table 3

Variability of morphological characteristics of sugar beet plants in vitro grown $(\mathrm{n}=3)$

\begin{tabular}{|c|c|c|c|c|c|}
\hline \multirow[b]{2}{*}{ Medium } & \multicolumn{4}{|c|}{ Number of regenerated plants with modified morphology, \% } & \multirow{2}{*}{$\begin{array}{c}\text { Total amount of } \\
\text { regenerated plants with } \\
\text { modified morphology, \% }\end{array}$} \\
\hline & leaf blades & leaf rosettes & root plants absorption & atypical root plants & \\
\hline Seed (control) & $0.9 \pm 0.2$ & $0.1 \pm 0.1$ & $2.2 \pm 0.2$ & $1.7 \pm 0.3$ & $4.9 \pm 0.3$ \\
\hline B5-A1-IAA & $0.8 \pm 0.2$ & - & $1.2 \pm 0.1$ & $1.1 \pm 0.1$ & $3.1 \pm 0.2$ \\
\hline B5-A2 -2.4-D & $1.1 \pm 0.1$ & - & $1.1 \pm 0.1$ & $1.1 \pm 0.1$ & $3.3 \pm 0.3$ \\
\hline B5-A3-2.4-DB & $0.5 \pm 0.1$ & $0.1 \pm 0.1$ & $1.7 \pm 0.1$ & $1.2 \pm 0.2$ & $3.5 \pm 0.2$ \\
\hline B5-NAA & $0.6 \pm 0.2$ & - & $0.8 \pm 0.2$ & $0.7 \pm 0.1$ & $2.1 \pm 0.1$ \\
\hline B5-A5-potassium salt NAA & $0.5 \pm 0.1$ & - & $1.3 \pm 0.1$ & $1.0 \pm 0.1$ & $2.8 \pm 0.2$ \\
\hline B5-A6-IBA & $0.6 \pm 0.1$ & - & $1.1 \pm 0.1$ & $1.3 \pm 0.2$ & $3.0 \pm 0.2$ \\
\hline
\end{tabular}

Studying the chromosomal mutations in cultivating sugar beet in vitro is a sophisticated task. The reason is that sugar beet (diploid set $2 \mathrm{H}=$ 18) chromosomes are poorly identified because of their small size and morphology similarity (Pillen et al., 1992; Beyaz et al., 2013). That is why cytometric control is mostly limited to establishing ploidy level and chromosomal aberrations. Cells with unbalanced number of chromosomes in the callusogenesis may arise in connection with indirect division in the callusogenesis (Dhooghe et al., 2011; Pasqual et al., 2012). Scientists of the Institute of Bioenergy Crops and Sugar Beet of National Academy of Agrarian Sciences have developed a method that allows the analysis to be performed of genome ploidy level variability of initial breeding materials of sugar beet with "Partec" ploidyanalyzer technology. However, we applied cytological methods of chemical components to determine the ploidy, since determining the ploidy using "Partec" analyser technology is relatively expensive (Trush et al., 2015).

In the variants where a bud was taken for the explants, in vitro proliferation was the most successful. Practically no chromosomal aberrations were observed in the test-tubed plants (Fig. 2). Spontaneous endoreduplication was observed within $0.25-0.47 \%$ under sugar beet cultivation in the media with ethylene and NAA, and in the absence of kinetin it amounted to $1.23 \%$ in some variants. Instead, there are papers (Sliwinska and Lukaszewska, 2005) which point out endoreduplication in coty-

Table 4

Cytometric parameters of sugar beet young roots (R1) $(n=3)$ ledons and leaves cells. Based on the idea that one of the key biochemical mechanisms of mitosis is a nucleic exchange, the different levels of hormones in plants grown in vitro compared to the control seeds had to affect the cells mitotic activity, which prompted us to study this issue.

Some cytogenetic characteristics of cells meristem of sugar beet young roots were obtained in the course of studying in vitro propagated sprouted seeds of MS-forms of Daryna hybrid pre-selected at low temperatures from sugar beet plants. That is, we studied the roots of sprouted seeds obtained by pollination of in vitro flower reproduced plant pollen with respective O-types pollen. The same MS-forms seed obtained in the traditional way were used for the control. It was found out that in vitro cultivation did not weaken and in some cases even increased the mitotic index of meristem cells of young sugar beet roots. In most of the genotypes the cultivation reduced the number of pathological mitosis, probably due to activation of repair systems, though it violated the duration of individual mitosis phases; it did not increase the number of anaphases with bridges and fragments, but changed the number of anaphases with other chromosomal abnormalities. In all the variants of the experiment where the growth process activation was noted, the lowest signs of variability was observed, i.e., cell populations unification obviously took place under the influence of stimulants that were parts of the nutrient media (Table 4).

\begin{tabular}{|c|c|c|c|c|c|c|}
\hline \multirow{2}{*}{ Genotypes } & \multirow{2}{*}{ Mitotic index, \% } & \multirow{2}{*}{ Pathological mitosis, \% } & \multicolumn{4}{|c|}{ Cells number by mitosis stages, \% } \\
\hline & & & prophase & anaphase & metaphase & telophase \\
\hline Seed control & $3.9 \pm 0.4$ & $0.3 \pm 0.1$ & $50.0 \pm 1.8$ & $27.6 \pm 2.1$ & $11.9 \pm 1.7$ & $10.5 \pm 0.8$ \\
\hline $585 \mathrm{k} 3$ & $3.3 \pm 0.5$ & $0.1 \pm 0.1$ & $47.3 \pm 2.9$ & $24.5 \pm 0.9$ & $14.0 \pm 1.5$ & $14.2 \pm 1.7$ \\
\hline $585 \mathrm{k} 10$ & $3.5 \pm 0.3$ & $0.6 \pm 0.2$ & $47.2 \pm 0.9$ & $30.7 \pm 1.5$ & $12.7 \pm 0.7$ & $9.4 \pm 1.2$ \\
\hline $587 \mathrm{k} 19$ & $3.5 \pm 0.5$ & $0.4 \pm 0.3$ & $45.0 \pm 2.4$ & $30.3 \pm 1.6$ & $14.4 \pm 1.6$ & $10.3 \pm 1.6$ \\
\hline $593 \mathrm{k} 11$ & $5.5 \pm 0.4$ & $0.7 \pm 0.6$ & $55.2 \pm 2.4$ & $22.6 \pm 2.0$ & $11.2 \pm 1.3$ & $11.0 \pm 0.9$ \\
\hline $597 \mathrm{k} 13$ & $3.0 \pm 0.2$ & $0.9 \pm 0.4$ & $53.3 \pm 1.5$ & $26.3 \pm 0.8$ & $10.0 \pm 1.9$ & $10.4 \pm 1.2$ \\
\hline $599 \mathrm{k} 16$ & $3.9 \pm 0.5$ & $0.3 \pm 0.1$ & $49.5 \pm 1.9$ & $29.2 \pm 1.6$ & $13.0 \pm 0.8$ & $8.3 \pm 1.4$ \\
\hline $621 \mathrm{k} 14$ & $3.6 \pm 0.4$ & $0.8 \pm 0.3$ & $50.3 \pm 1.7$ & $14.8 \pm 0.5$ & $19.6 \pm 1.6$ & $15.3 \pm 0.6$ \\
\hline 585 k 3 & $4.2 \pm 0.1$ & $0.5 \pm 0.2$ & $46.5 \pm 1.9$ & $32.2 \pm 1.6$ & $13.0 \pm 0.8$ & $8.3 \pm 1.4$ \\
\hline $585 \mathrm{k} 10$ & $4.8 \pm 0.2$ & $0.4 \pm 0.1$ & $50.2 \pm 2.0$ & $29.6 \pm 1.5$ & $11.2 \pm 1.8$ & $9.0 \pm 0.3$ \\
\hline $585 \mathrm{k} 10$ & $3.9 \pm 0.5$ & $0.6 \pm 0.4$ & $47.1 \pm 03$ & $27.4 \pm 0.7$ & $15.2 \pm 1.2$ & $10.3 \pm 0.9$ \\
\hline 589 k 19 & $3.1 \pm 0.4$ & $0.1 \pm 0.1$ & $48.6 \pm 0.6$ & $26.8 \pm 0.7$ & $14.6 \pm 1.9$ & $10.0 \pm 0.9$ \\
\hline $597 \mathrm{k} 13$ & $5.3 \pm 0.3$ & $0.8 \pm 0.4$ & $57.2 \pm 2.0$ & $29.6 \pm 1.5$ & $7.2 \pm 0.7$ & $6.0 \pm 0.2$ \\
\hline $597 \mathrm{k} 17$ & $3.6 \pm 0.5$ & $0.6 \pm 0.2$ & $48.0 \pm 0.8$ & $32.1 \pm 2.2$ & $11.4 \pm 1.1$ & $8.5 \pm 0.3$ \\
\hline $613 \mathrm{k} 19$ & $4.8 \pm 0.1$ & $0.6 \pm 0.3$ & $52.2 \pm 0.3$ & $24.6 \pm 0.6$ & $13.2 \pm 1.8$ & $10.0 \pm 0.7$ \\
\hline 617 k 6 & $4.1 \pm 0.3$ & $0.6 \pm 0.2$ & $50.2 \pm 1.8$ & $20.6 \pm 0.9$ & $16.2 \pm 0.4$ & $13.0 \pm 1.1$ \\
\hline 583 k 7 & $3.3 \pm 0.5$ & $0.2 \pm 0.1$ & $42.7 \pm 0.3$ & $29.1 \pm 1.6$ & $16.0 \pm 1.2$ & $12.2 \pm 0.4$ \\
\hline 617 k 6 & $3.5 \pm 0.2$ & $0.3 \pm 0.1$ & $48.4 \pm 2.9$ & $26.5 \pm 0.9$ & $14.0 \pm 1.5$ & $11.1 \pm 1.7$ \\
\hline 617 k 19 & $6.1 \pm 0.4$ & $0.7 \pm 0.2$ & $58.2 \pm 2.6$ & $18.6 \pm 1.8$ & $12.2 \pm 1.1$ & $11.0 \pm 0.4$ \\
\hline
\end{tabular}

Therefore, it seems logical to assume that the increase in somaclonal variability in vitro, described primarily for in vitro genotypes lodging, can result from the influence of retardants used in the lodged cultures. As the subsequent observations reveal, microcloning does not increase the number of chromosomal aberrations and minor deviations in setting up the bridges, fragments and micronuclei do not exceed the limits of the experiments precision. The reasons for such stability have not been clarified, as it is also not clear whether the observed chromosomal aberrations cultured in vitro differ qualitatively. Manifestations of some of them already in the early stages of cell division suggests that the lack of clear rules is mainly the result of the stabilization of intracellular hormonal environment in its preparation for the separation, i.e. in the pre-start phase of the cell cycle (in interphase).

\section{Conclusions}

According to the data of the dispersion analysis, the modified media by auxins can be grouped into three groups of effectiveness by the 
number of rooted microcloons. The first is attributed to the NOC, to the second - media with 2,4-D, 2,4-DB, potassium salt NAA and IBA, to the third - IAA. For subcultivation of inoculated seedlings which are cultivated in vitro, the nutrient medium B5-173 was found to be the best of the studied media, in which in conditions of excellent sterilization, microcrotones of sugar beets rooted better.

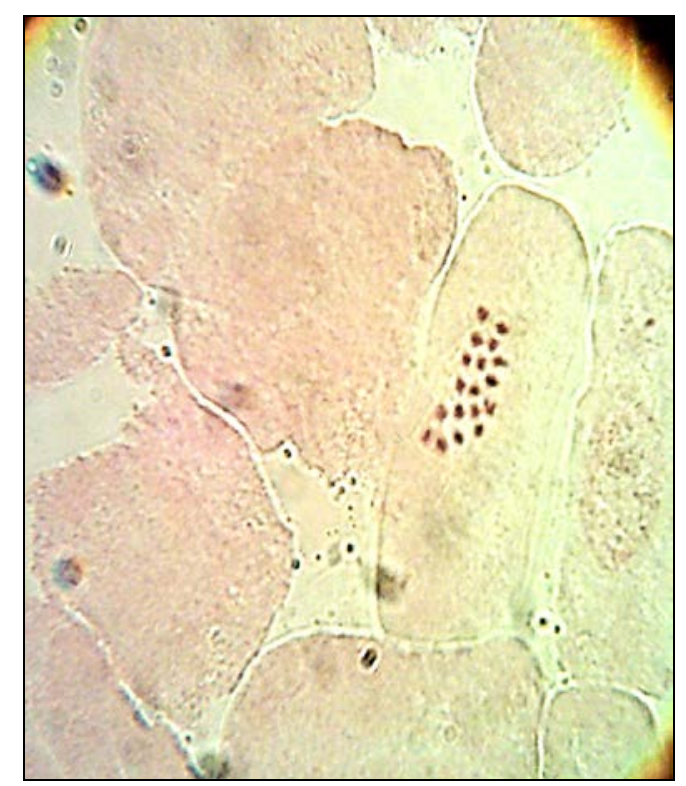

Fig. 2. Normal diploid chromosomal complement

in the test-tubed plant regenerants of sugar beet

number $585 \mathrm{k} 10$ grown in the field after ex vitro adaptation

The possibility of regulation of the growth and development of sugar beet explants in vitro in favour of undifferentiated growth during proliferation or organogenesis (hemo- and rhizogenesis) in the stage of the formation of roots or shoots has been found. The study confirmed the benefits of rooting the regenerant plants of sugar beet according to our method of darkening the agar culture medium using dye methylene blue at a concentration of $0.05 \%$ and owing to reducing the inhibitory light impact on the development of lateral roots, the average rooting in the microclones of MS-form reached $81.5 \%$. The technology of the rooted microclones adaptation ensuring survival of plant-regenerants to $87 \%$ has been developed. The tasks of accelerated sugar beet in vitro breeding from fresh harvested seed in the adverse off-season period with prevention of somaclonal mutation has been completed and thus, obtaining genetically homogeneous maternal MS-forms of Daryna heterosis hybrid can be guaranteed.

This study is partly based on the work supported by the Uman National University of Horticulture (No 0111U005405) in compliance with their thematic plans of research work. We thank Professor Anatoly I. Opalko, $\mathrm{PhD}$ in Agriculture, leading researcher of the Genetics, Plant breeding and Reproductive Biology Division of the National Dendrological Park "Sofiyivka" of the National Academy of Sciences of Ukraine for consultations and discussion.

\section{References}

Beyaz, R., Alizadeh, B., Gürel, S., Özcan, S. F., \& Yildiz, M. (2013). Sugar beet (Beta vulgaris L.) growth at different ploidy levels. Caryologia, 66(1), 90-95.

Dhooghe, E., Van Laere, K., Eeckhaut, T., Leus, L., \& Van Huylenbroeck, J. (2011). Mitotic chromosome doubling of plant tissues in vitro. Plant Cell, Tissue and Organ Culture, 104(3), 359-373.

Gürel, E., \& Wren, M. J. (1995). In vitro development from leaf explants of sugar beet (Beta vulgaris L). Rhizogenesis and the effect of sequential exposure to auxin and cytokinin. Annals of Botany, 75(1), 31-38.

Gurel, E., Gurel, S., \& Lemaux, P. G. (2008). Biotechnology applications for sugar beet. Critical Reviews in Plant Sciences, 27(2), 108-140.

Joersbo, M. (2007). Sugar beet. In: Pua, E. C., \& Davey, M. R. (Eds.). Biotechnology in Agriculture and Forestry, Transgenic Crops, Springer-Verlag, Berlin, 59, 355-378.
Kagami, H., Taguchi, K., Arakawa, T., Kuroda, Y., Tamagake, H., \& Kubo, T. (2016). Efficient callus formation and plant regeneration are heritable characters in sugar beet (Beta vulgaris L.). Hereditas, 153(1), 12.

Klyachenko, O. L., Lichanov, A. F., \& Krylovskaya, S. A. (2012). Cell regulation of morphogenic processes in the callus tissues of sugar beet in vitro conditions. Bulletin of Agrarian Science, 12, 48-50 (in Ukrainian).

Kolomiets, Y. V. (2008). Clonal microprosthetics of sugar beet in vitro: possibilities for reproduction and preservation of biological diversity. Scientific Support of NAU, 1(9), 1-14.

Kosenko, I. S., Opalko, A. I., \& Nebykov, M. V. (2008). Regeneration of plants in the process of micropropagation. Autochthonous and Alien Plants, 3-4, 5767 (in Ukrainian).

Krylovskaya, S. A. (2012). Features of in vitro sugar beet morphogenesis (Beta vulgaris L.). Collection of scientific works of Institute of Bioenergetic Cultures and Sugar Beets, 14, 461-465 (in Ukrainian).

Mezei, S., Kovacev, L., \& Nagl, N. (2006). Sugar beet micropropagation. Biotechnology and Biotechnological Equipment, 20, 9-14.

Miguel, C., \& Marum, L. (2011). An epigenetic view of plant cells cultured in vitro: Somaclonal variation and beyond. Journal of Experimental Botany, 62(11), 3713-3725.

Mishutkina, Y. V., \& Gaponenko, A. K. (2006). Study of the influence of nutrient medium composition, explant type and genotype on the frequency of regeneration of sugar beet plants (Beta vulgaris L.) in vitro. Genetics, 42(2), 210 218 (in Ukrainian).

Mishutkina, Y. V., \& Gaponenko, A. K. (2006). Sugar beet (Beta vulgaris L.) morphogenesis in vitro: Effects of phytohormone type and concentration in the culture medium, type of explants, and plant genotype on shoot regeneration frequency. Russian Journal of Genetics, 42(2), 150-157.

Nagl, N., Maksimovic, I., Curcic, Z., Putnik-Delic, M., \& Kovacev, L. (2010). Effect of induced water deficit on sugar beet micropropagation. In: Proceedings of 72nd IIRB Congress. (22th-24th Jun, 2010, Copenhagen, Denmark). Intemational Institute for Beet Research (IIRB), Bruxelles, Belgium. pp. 179-185.

Neelwarne, B. (2013). Cell and tissue culture studies in Beta vulgaris L. In: Neelwarne, B. (Ed.). Red beet biotechnology. Springer Science + Business Media, New York, pp. 175-198.

Pasqual, M., Pio, L. A. S., Oliveira, A. C. L., \& Soares, J. D. R. (2012). Flow cytometry applied in tissue culture. Leva, A., \& Rinaldi, L. M. R. (Eds.): Recent advances in plant in vitro culture (Ch. 6), In Tech Prepress, Novi Sad, pp. 109-122.

Penna, S., Vitthal, S. B., \& Yadav, P. V. (2012). In vitro mutagenesis and selection in plant tissue cultures and their prospects for crop improvement. Bioremediation, Biodiversity and Bioavailability: Global Science Books, 6(1), 6-14.

Pillen, K., Steinrücken, G.,Wricke, G., Herrmann, R. G., \& Jung, C. (1992). A linkage map of sugar beet (Beta vulgaris L.). Theoretical and Applied Genetics, 84(1), 129-135.

Polischuk, V. V., Polischuk, O. V., \& Karpuk, L. M. (2012). Selection of nutrient medium for sugar beet cms component introduction and proliferation. Autochthonous and Introduced Plants of Ukraine, 8, 123-128 (in Ukrainian).

Polishchuk, V. (2012). Seedlings sterilisation of parental forms of sugar beets hybrids for input in vitro. Agrobiology, 9, 45-48 (in Ukrainian).

Putnik-Delic, M., Maksimovic, I., Venezia, A., \& Nagl, N. (2013). Free proline accumulation in young sugar beet plants and in tissue culture explants under water deficiency as tools for assessment of drought tolerance. Romanian Agricultural Research, 30, 141-148.

Ritchie, G. A, Short, K. C., \& Davey, M. R. (1989). In vitro shoot regeneration from callus, leaf axils and petioles of sugar beet (Beta vulgaris L.). Journal of Experimental Botany, 40, 277-283.

Rizkalla, A. A., Badr-Elden, A. M., Ottai, M. E. S., Nasr, M. I., \& Esmail, M. N. (2012). Development of artificial seed technology and preservation in sugar beet. Sugar Tech, 14(3), 312-320.

Ryabovol, L. O. Ryabovol, Y. S., \& Lyubchenko, A. I. (2012). Nutrient medium for rooting homozygous material of sugar beet. Collection of scientific works of Uman National University of Horticulture, 81(1), 196-199.

Sullivan, C. F., Finch, I., Dix, P. J., \& Burke, J. I. (1993). Studies of in vitro propagation systems for sugar beet. Irish Journal of Agricultural and Food Research, 32, 27-35.

Taski-Ajdukovic, K., Nagl, N., Kovacev, L., Curcic, Z., \& Danojevic, D. (2012). Development and application of qRT-PCR for sugar beet gene expression analysis in response to in vitro induced water deficit. Electronic Journal of Biotechnology, 15(6), 10.

Tomaszewska-Sowa, M. (2012). Effect of growth regulators and other components of culture medium on morphogenesis of sugar beet (Beta vulgaris L.) in unfertilised ovule in vitro cultures. Acta Agrobotanica, 65(4), 91-100.

Trush, A. O., Perfenyuk, S. G., \& Tatarchuk, V. M. (2015). The efficiency of different methods of cytological control of the ployidity of multi-growth tetraploid plasters of sugar beet in the selection of triploid hybrids on the basis 
of the CMF. Collection of Scientific Works of Uman National University of Horticulture, 87(1), 176-182 (in Ukrainian).

Us-Camas, R., Rivera-Solís, G., Duarte-Aké, F., \& De-la-Pena, C. (2014). In vitro culture: An epigenetic challenge for plants. Plant Cell Tissue and Organ Culture, 118(2), 187-201.

Wright, T. R., \& Penner, D. (1998). Cell selection and inheritance of imidazolinone resistance in sugarbeet (Beta vulgaris). Theoretical and Applied Genetics, 96(5), 612-620.
Yildiz, M., Alizadeh, B., \& Beyaz, R. (2013). In vitro explant growth and shoot regeneration from petioles of sugar beet (Beta vulgaris L.) lines at different ploidy levels. Journal of Sugar Beet Research, 50, 22-36.

Zhang, C. L., Chen, D. F., Elliott, M. C., \& Slater, A. (2001). Thidiazuron-induced organogenesis and somatic embryogenesis in sugar beet (Beta vulgaris L). In Vitro Cellular and Developmental Biology - Plant, 37(2), 305-310. 